\title{
Cerebellar Ectopia Presenting in Adult Life
}

\author{
JULIUS SMITH,* M.R.C.P., D.M.R.D., F.F.R. ; ALAN RIDLEY, $\dagger$ M.D., PH.D., M.R.C.P.
}

[With Special Plate]

Brit. med. 7., 1969, 1, 353-355

\begin{abstract}
Summary : Three cases of cerebellar ectopia first pro$\$$ ducing symptoms in adult life are reported. This potentially remediable anomaly may not be suspected in adults, in whom associated congenital bony abnormalities of the skull and cervical spine are often absent. In these cases diagnosis depends on radiological contrast studies; in particular it is important to examine the cervical canal in the prone and supine positions.
\end{abstract}

\section{Introduction}

The syndrome resulting from congenital abnormalities at the craniospinal junction have been reviewed by Garcin and Oeconomos (1953) and by Spillane, Pallis, and Jones (1957). One important potentially remediable abnormality of this region is cerebellar ectopia. ${ }^{1}$

It is important to be aware that cerebellar ectopia may be sy:nptomless until adult life and that it may be present without any bony abnormality of the skull or spine. The anomaly in this group of cases can be demonstrated only by radiological contrast studies. The introduction of routine supine positive contrast myelography has led to the recognition of many unsuspected cases and emphasized that the condition is not rare even in the fifth and sixth decades.

The present communication reports three cases seen in the neurological department of an undergraduate teaching hospital during a two-year period. The severity of the clinical syndrome and the unfortunate death of a previously healthy 33-year-old woman prompted us to report these cases and to draw attention to some of the difficulties in diagnosis.

\section{Case 1}

A 51-year-old railway worker was first seen in November 1964 with a six-month history of giduiness and unsteadiness of gait. His speech had been slurred at times, and for two months he had had pain and stiffness in the right side of the neck and right arm. On examination both biceps and supinator jerks were absent and there was nystagmus on looking to the right. Neck movements were full and painless, but radiologically there was narrowing of

* Assistant Radiologist, National Hospital, Queen Square, London W.C.1. Formerly Senior Registrar, Radiological Department, University College Hospital, London W. C.1.

+ Senior Registrar, Neurological Unit, University College Hospital, London W.C.

1 The complex developmental anomaly involving the cerebellum and brain stem is commonly known as the Arnold-Chiari malformation. Chiari (1891) described the case of a child in whom the fourth Chiari (1891) described the case of a child in whom the fourth
ventricle was displaced downwards to the level of the fifth cervical ventricle was displaced downwards to the level of the fifth cervical
vertebra. Arnold (1894) described several cases of maldevelopment vertebra. Arnold (1894) described several cases of maldevelopment of the cerebellum with associated hydrocephalus and myelocele. Chiari (1896) in the now classical paper included accounts of 21
cases. However, Professor J. Cletand (1883) described dissections cases. However, Professor J. Cletand (1883) described dissections of nine "imperfections" of the brain and spinal cord. The anomaly is clearly described in his paper and we feel that if an eponymous title is to be used for this condition due recognition should be given Spillane et al. (1957), is probably preferable to an eponymous title embracing the names of Cleland, Chiari, and Arnold. the C 5-6 disc space. A diagnosis of cervical spondylosis with vertebrobasilar insufficiency was made and a cervical collar fitted During the next four months his condition deteriorated; his gait became more ataxic, numbness and paraesthesia developed in the hands, which became clumsy, holding a knife and fork became difficult, and he was unable to recognize objects by feeling them. On several occasions he burnt his fingers while stubbing out cigarettes. In addition he developed dysphagia; fluids and soft foods would stick at the back of his throat, causing him to cough and splutter.

On examination of the cranial nerves at this stage nystagmus to both left and right, sluggish corneal reflexes, and bilateral weakness of the tongue and palate were found. There was marked incoordination of all four limbs. Tone was increased in the arms, and the triceps, knee, and ankle jerks were increased. The left plantar response was weakly extensor and the abdominal reflexes were preserved. Sensory examination showed bilateral spinothalamic impairment from $C 3$ to $C 8$, and there was marked impairment of position sense in both hands and, to a less extent, in the feet. Vibration sense was diminished at the fingers and wrists and below the knees.

On 8 March 1965 a myelogram showed obstruction at the foramen magnum by an elongated rounded mass extending below C 1 (Special Plate, Figs. 1 and 2). Soon after myelography the patient developed stridor, and on 10 March a suboccipital craniectomy and upper cervical laminectomy was carried out. The left cerebellar tonsil projected down through the foramen magnum to the lower border of the atlas. The right tonsil was swollen and herniated, but to a less degree. No evidence of a tumour was found, and the wound was closed with the dura left open. Postoperatively the stridor became worse. Laryngoscopy showed bilateral abductor paralysis and a tracheostomy was performed. Convalescence was complicated by a lung abscess, but during the month following operation the spinothalamic sensory disturbance regressed from $\mathrm{C} 8$ to $C 5$ and incoordination of the upper limbs improved. Gait also became less ataxic, but at discharge in Aprill 1965 he could still wadk only with considerable difficulty. The vocal chord paralysis did not recover and trachenstomy had to remain a permanent feature.

\section{Case 2}

A nursery assistant presented in 1955 at the age of 18 with an 8-month history of weakness and pain in her left arm and hand, in which there was a constant cold feeling. At the age of 10, after a mass $x$-ray examination, she had been told that she had a kink in her spine. Examination in 1955 showed weakness of all movements of the left upper limbs except shoulder adduction. On the left side the scapula was winged and the spinati, rhomboids, deltoid and biceps were wasted. Tone and tendon reflexes were increased in the left arm and both legs, with bilateral extensor plantar responses and absent abdominal reflexes. In the right arm tone and reflexes were normal. Spinothalamic sensory impairment was present bilaterally from $C 3$ down to $C 4$ on the left and to $T$ on the right. Position sense was defective in the feet and vibration sense was impaired below the knee. There was a marked thoracolumbar scoliosis and bilateral pes cavus. Straight $x$-ray films showed bilateral cervical ribs. A myelogram showed a dilated cord, but the upper cervical canal was not adequately examined (Special Plate, Figs. 3 and 4). A diagnosis of syringomyelia was made and the cervical card irradiated.

During the next 10 years the left upper limb became completely paralysed but the tendon reflexes remained brisk. Wasting of both 
sternomastoids and trapezii occurred and the spinothalamic sensory loss spread on the right side up over the cheek and !own to L 1 . The lower limbs became increasingly spastic. In 1965, after a fall caused by tripping over a kerbstone, the right hand was weak for several months.

On 21 July 1966 she was admitted to hospital deeply cyanosed and apnoeic after falling from a moving bus. Endotracheal intubation was necessary for 20 minutes before spontaneous respiration returned. Immediately after the accident the right upper limb became paralysed and the weakness of both legs increased. Cervical $x$-ray films were normal. Repeat myelography was considered, but on 27 July she became apnoeic and was transferred to the National Hospital, Queen Square. There, because of major alterations in the radiology department, myelography could not be undertaken and an emergency upper cervical laminectomy was performed. The arachnoid membrane was thickened, and enlarged cerebellar tonsils were displaced down into the forau sion, assisted respiration was necessary and had to be continued for two months. At discharge in October 1966 power in the right upper limb had improved a little so that she could hold a pen, but the spinothalamic sensory loss and spastic paraparesis were unchanged. Her ventilatory capacity remained subnormal and permanent tracheostomy was necessary.

\section{Case 3}

A 33-year-old married West Indian domestic began in April 1966 to complain of suboccipital pain and generalized headaches. A month later her gait became unsteady. The headaches and ataxia' increased and she developed vertigo and paraesthesia in the hands. Since a tonsillectomy in 1964 she had complained of intermittent dysphagia, and this now became worse. By July she was so ataxic she could not walk unaided, and on 14 July she was referred and immediately admitted to hospital with a tentative diagnosis of posterior fossa tumour. Examination showed slight slurring of speech and marked horizontal nystagmus on lateral gaze, particularly to the right, with slight vertical nystagmus on looking up. The palate was weak bilaterally. Apart from a little ataxia of the left arm, co-ordination of the limbs when tested individually was surprisingly good. There was a mild spastic quadriparesis. Sensation was normal. Slight occipital tenderness was noted. $X$-ray films of the skull were normal, but the body of the fifth cervical vertebra was bifid.

Shortly after her admission the headaches lessened and the diagnosis of posterior fossa tumour was questioned. It was decided to keep her in bed under observation for a few days. Her symptoms continued to improve and by the end of a week she could walk unaided. On 25 July a lumbar air encephalogram was performed. The spinal fluid pressure was normal and air passed over the surface of the cerebral hemisphere, but could not be made to enter the ventricular system. Iophendylate introduced by the lumbar route also failed to enter the ventricles. After the air study she became drowsy and had increasing difficulty in swallowing. On 28 July she was apnoeic for five minutes. The next day a ventriculogram was carried out. The lateral ventricles and third ventricle were normal. The aqueduct was not clearly seen, but the fourth ventricle was outlined and was thought to be normal in size but low in position. The patient was returned to the ward. During the next three days her speech became nasal, fasciculation appeared on both sides of the tongue, the pharyngeal reflex disappeared, and fluctuating weakness of the left arm and leg occurred.

On 1 August the bulbar symptoms necessitated tracheostomy. At this stage the iophendylate films were reviewed and it was realized that the cerebellar tonsils were displaced down to the upper border of the second cervical vertebra (Special Plate, Fig. 5). On 5 August the craniospinal junction was explored. A tough fibrous band firmly adherent to the dura extended across the cervical canal at the level of $\mathrm{C} 2$. It was not possible to dissect this band from the dura. On opening the dura the right cerebellar tonsil was seen to extend down to C 2. After amputating this tonsil cardiac arrest occurred. The heart was restarted with difficulty and it was decided to terminate the operation. Twenty-four hours later fatal cardiac arrest occurred. At necropsy there was some subarachnoid blood at the site of the operation, but no other abnormality was found in the brain.

\section{Discussion}

The clinical features of cerebellar ectopia have been ascribed by Sp:llane et al. (1957), who pointed out that the condition may first present in adult life in the absence of other signs of congenital abnormality of the craniospinal junction, such as a short neck and hydrocephalus. Diagnosis in these circumstances may be difficult, as Case 3 illustrates. The late onset of symptoms in Case 1 is noteworthy and emphasizes the importance of bearing the condition in mind even in quite old adults.

Spinothalamic sensory loss (Cases 1 and 2) is a wellrecognized sign of foramen magnum lesions (Symonds and Meadows, 1937 ; Garcin and Oeconomos, 1953). It is often associated with marked postural loss of the upper limbs (Case 1), but when occurring by itself may lead to a mistaken diagnosis of syringomyelia.

Case 2 had undoubted cerebellar ectopia, and the swollen cervical cord was almost certainly due to associated syringomyelia.

Gardner and Goodall (1950) and Gardner, Abdullah, and McCormack (1957) have emphasized the relation between the two conditions. Though syringomyelia and its association with hydrocephalus or posterior fossa malformations have been frequently reported in the past the connexion had often been overlooked.

Gardner and his colleagues considered cerebellar ectopia, diverticula, and cysts of the outlets of the fourth ventricle and the Dandy-Walker syndrome to be varying expressions of embryonal atresia of the fourth ventricle. In each of their 74 cases of syringomyelia in which the posterior fossa was explored such malformations were found.

A useful sign, the significance of which was not appreciated in Case 3, is pain and tenderness in the suboccipital region. Symonds and Meadows (1937) drew attention to this feature in extramedullary tumours in the neighbourhood of the foramen magnum.

Patients with cerebellar ectopia are particularly at risk from cervical trauma (Spillane et al., 1957). Even trivial neck injuries may have grave consequences, as shown in Case 2. The jolt to the patient's neck caused by tripping over a kerbstone resulted in weakness of her right hand for several months, and her disability increased after a relatively minor head injury. On the other hand, spontaneous improvement may occur. The improvement with bed rest shown in Case 3 was misleading, and for a time it was thought that the patient had multiple sclerosis. Such fluctuation in the clinical picture of patients with cerebellar ectopia is almost certainly due to changes in cerebrospinal fluid dynamics. One possible explanation of the beneficial effects of bed rest is that when lying in bed the head tends to be flexed forward and in this position there is least compression of the displaced hindbrain. Wickbom and Hanafee (1963) showed that with the head in the flexed position the space between the ectopic tonsils and the rim of the foramen magnum is greater than when the head is erect.

Straight $x$-ray films of the skull and cervical spine may show congenital abnormalities or evidence of raised intracranial pressure (erosion of dorsum sellae, suture diastasis, etc.). On the other hand, they may be quite normal. In 6 of the 17 cases described by Appleby, Foster, Hankinson, and Hudgson (1968), and in 3 of the 21 cases published by Hugh Davies shortly after his death (Davies, 1967), plain skull and cervical spine $x$-ray films were completely normal.

List (1941) first demonstrated cerebellar ectopia by positive contrast radiology. Baker (1963) suggested that examination of the foramen magnum and hindbrain with Pantopaque (iophendylate) was simple and extremely helpful ; in 204 cases with high cervical cord symptoms he found 11 cases of 
JULIUS SMITH AND ALAN RIDLEY: CEREBELLAR ECTOPIA PRESENTING IN ADULT LIFE

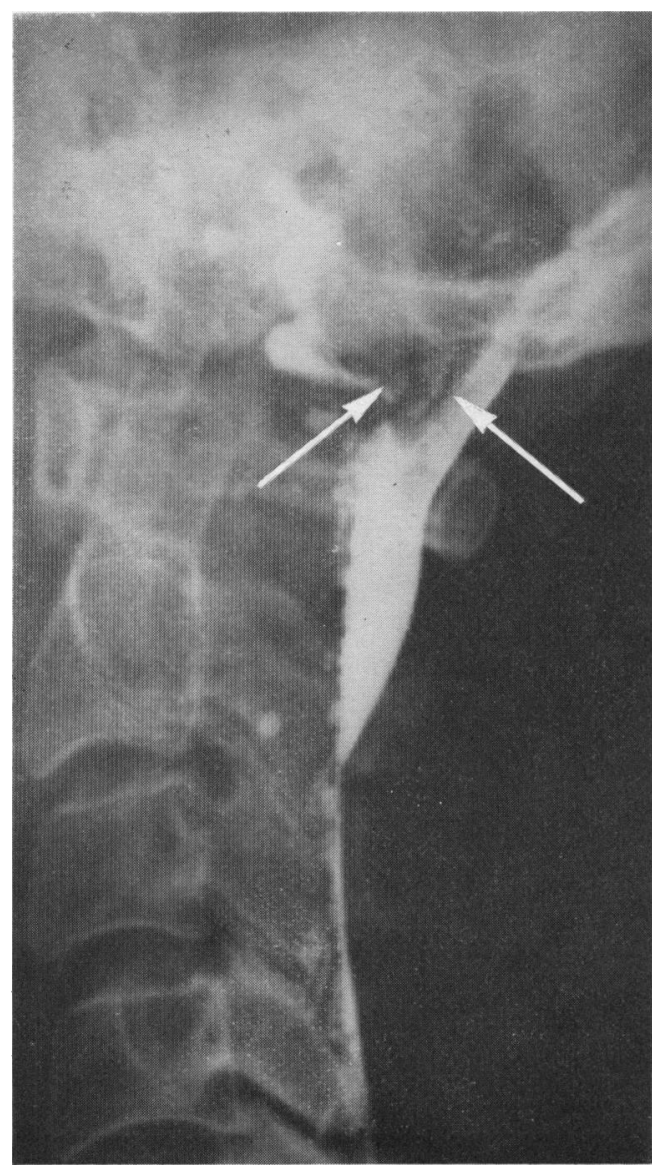

FIG. 1.-Case 1. Supine myelogram showing herniated tonsils (lateral)

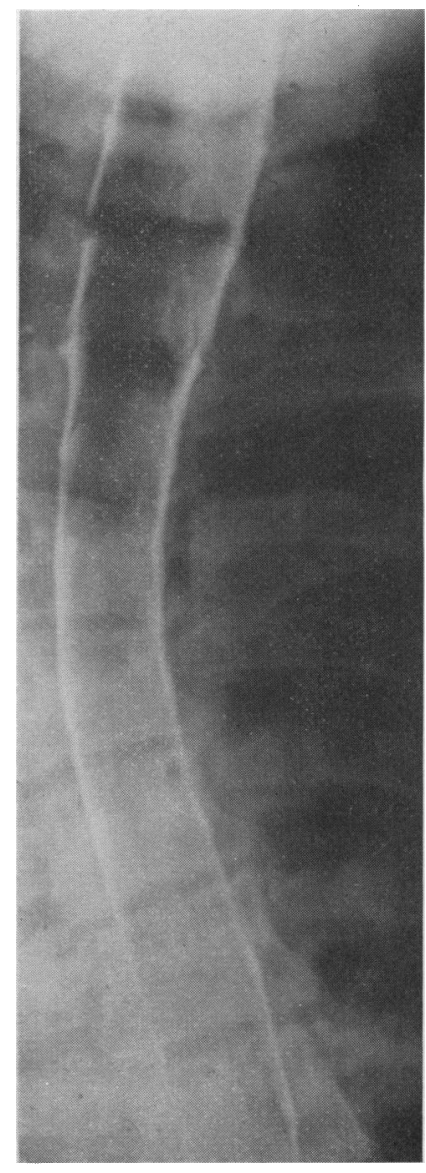

Fig. 3.-Case 2. Myelogram showing extensive hydromyelia.

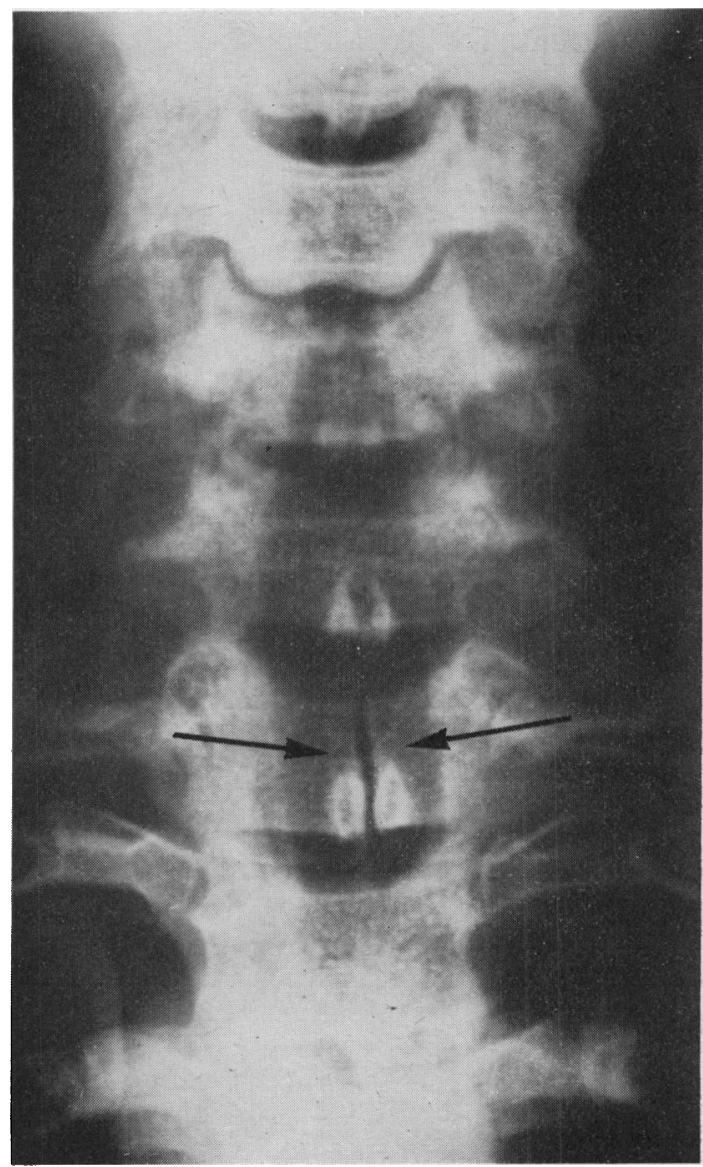

Fig. 4.-Case 2. Cervical spina bifida.

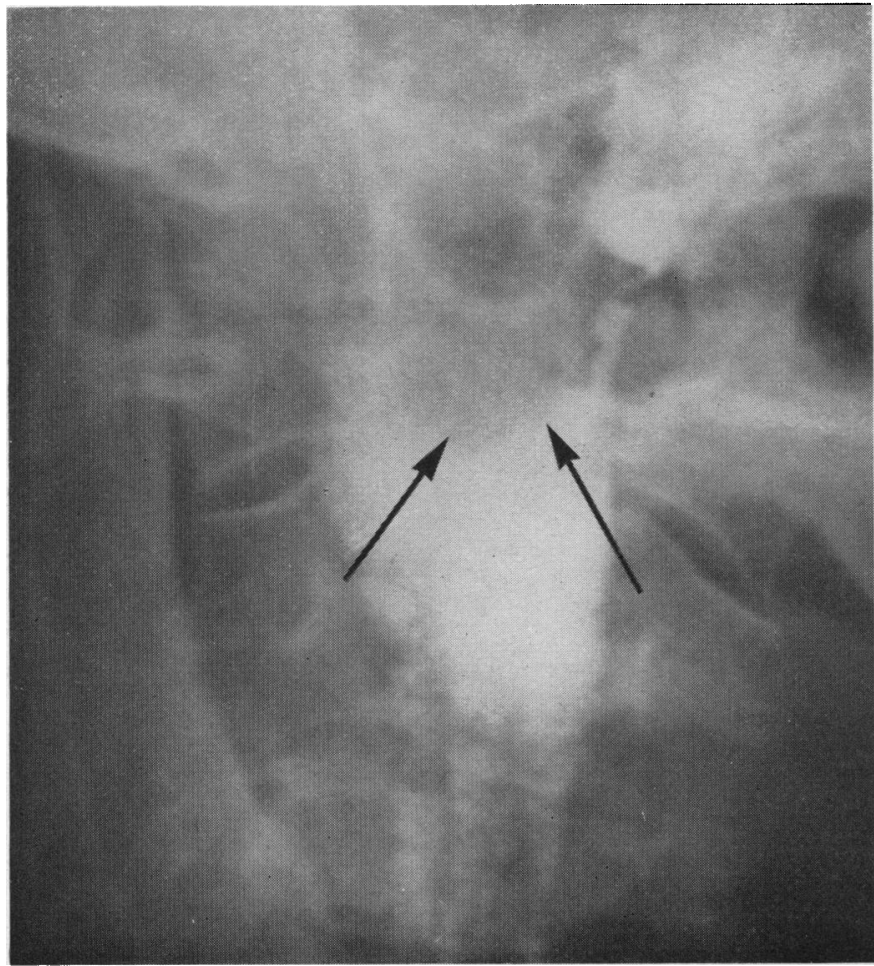

FIG. 2.-Case 1. Supine myelogram showing herniated tonsils predominantly on left side.

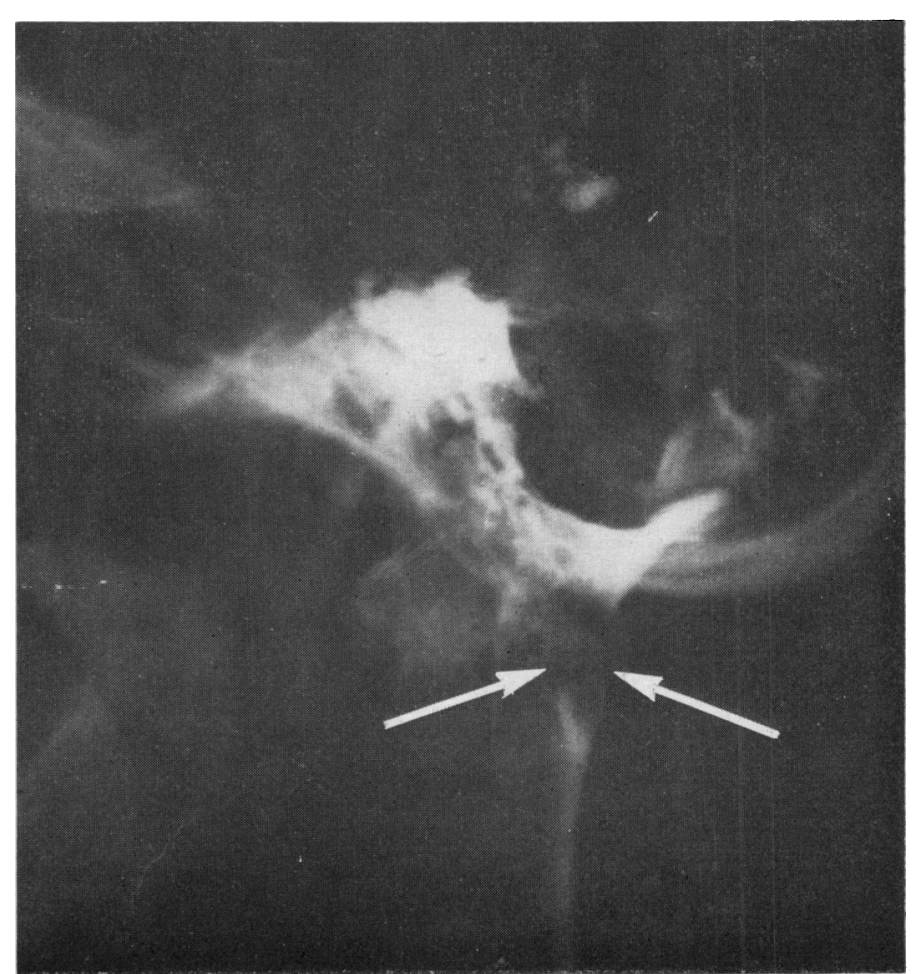

FIG. 5.-Case 3. Supine myelogram showing herniated tonsils extending down to $\mathrm{C} 2$. 
cerebellar ectopia. The value of negative contrast studies was emphasized by Wickbom and Hanafee (1963), who analysed the findings of 418 air encephalograms carried out for suspected intracranial space-occupying lesions and found six type 1 and one type 2 anomaly. In Sweden, France, Italy, and Germany air myelography is the method of choice, and iophendylate is rarely used. Jirout (1966) performed air myelography with the patient sitting and the head flexed well forwards.

The classical appearance of the herniated tonsils in cerebellar ectopia is tongue-shaped as described by Liliequist (1960). Unfortunately, occasionally, as in Case 1, the tonsils are not of this shape and are impossible to distinguish from herniated tonsils secondary to raised intracranial pressure. In patients presenting with the disorder in middle life it is imperative to exclude a tumour, and clearly the rest of the posterior fossa and also the cerebral hemisphere must be examined either by air myelography or by arteriography before performing a decompression.

In the non-acute case neuroradiological studies may be performed without risk and at leisure. However, in acute cases investigations may be hazardous. Thus in Case 3 the performance of an air study which failed to outline the fourth ventricle and an iophendylate myelogram, followed shortly afterwards by ventriculography, undoubtedly contributed to the eventual fatal outcome. It is suggested that when sudden deterioration occurs in such a case only one examination should be carried out and posterior fossa decompression performed. The radiologist (J.S.) involved in Case 3, while aware that the fourth ventricle was low, was bent on excluding a lesion pushing it down. This is an extremely common clinical problem. Awareness that the malformation alone may produce such a gross clinical picture is important and may help to prevent similar unfortunate errors.
The importance of adequately examining the upper cervical canal in both the prone and the supine position has been stressed by Baker (1963) and E. G. P. H. du Boulay (personal communication, 1966). Unfortunately, this is by no means routine even with syndromes suggesting upper cervical cord involvement. It is difficult to be dogmatic about whether supine positive contrast myelography is superior to gas myelography. The former is simple and requires no special equipment. The latter is more refined, more time-consuming, and requires special equipment. However, it demonstrates the anatomy so much better that we feel that it will eventually become the method of choice.

We wish to thank Dr. W. Gooddy, Dr. G. Stern, Mr. B. Harries, and $\mathrm{Mr}$. K. Till for permission to publish cases under their care. We are also grateful to Dr. Stern for helpful advice and criticism. One of us (J.S) would like to express his gratitude to Dr. G. H. du Boulay, who first brought home to him the importance of supine myelography in upper cervical syndromes.

\section{REFERENCES}

Appleby, A., Foster, J. B., Hankinson, J., and Hudgson, P. (1968). Brain, 91, 131 .

Arnold, J. (1894). Beitr. path. Anat., 16, 1.

Baker, H. L. (1963). Radiology, 81, 791.

Chiari, H. (1891). Dtsch. med. Wschr., 17, 1172

Chiari, H. (1896). Denkschr. Akad. Wiss., Wien, 63, 71.

Cleland, J. (1883). F. Anat., 17, 257 .

Davies, H. W. (1967). Brit. F. Radiol., 40, 262

Garcin, R., and Oeconomos, D. (1953). Les aspects neurologiques des malformations congénitales de la charnière craniorachidienne. Gardner, W. J., Abdullah, A. F., and McCormack, L. J. (1957). 3. Neurosurg., 14, 591.

Gardner, W. J., and Goodall, R. J. (1950). F. Neurosurg., 7, 199.

Jirout, J. (1966). Neuroradiologie. Berlin.

Liliequist, B. (1960). Acta Radiol., 53, 17.

List, C. F. (1941). Arch. Neurol. Psychiat. (Chic.), 45, 577.

Spillane, J. D., Pallis, C., and Jones, A. M. (1957). Brain, 80, 11

Symonds, C. P., and Meadows, S. P. (1937). Brain, 60, 52 .

Wickbom, I., and Hanafee, W. (1963). Acta radiol. (Diag.), 1, 647.

In view of the present interest in asbestosis it was considered that an attempt should be made to correlate the asbestos count on histological section with the pulmonary radiographic find-

ings, with a view to discovering if there is a level at which evidence of asbestosis becomes discernible on a chest radiograph.

Earlier reports have shown that the incidence of asbestos bodies found in lung smears at routine necropsy has varied from 20 to $47 \%$ (Cauna, Totten, and Gross, 1965 ; Anjilvel and Thurlbeck, 1966 ; Thomson and Graves, 1966 ; Roberts, 1967 ; Ashcroft, 1968), while the incidence in histological section of lung tissue has ranged from 6 to $58 \%$ (Hourihane, 1964 ; Meurman, 1966 ; Gibson, McEwen, Finlayson and Mair, 1968). Elmes and Bell (1968) point out that the inhaled asbestos is distributed comparatively evenly throughout both lungs and have shown that histological section of one segment of lung is representative of pulmonary tissue.

\section{Material and Method}

The report of Gibson et al. (1968) included the findings of 600 consecutive necropsies at the Western Infirmary, Glasgow. Lung was sampled from the base of either lower lobe and histological examination made of a single unstained 30-micron 